\title{
Gap Analysis Survey: An Aid in Transitioning to Standardized Curricula for Nuclear Medicine Technology
}

\author{
Angela Macci Bires, CNMT, RT(N) ${ }^{1}$, Donna L. Mason, CNMT, RT(N) ${ }^{1}$, David Gilmore, CNMT, RT(R)(N), FSNMTS ${ }^{2}$, \\ and Carly Pietrzyk ${ }^{3}$ \\ ${ }^{I}$ Nuclear Medicine Technology Program, Robert Morris University, Moon Township, Pennsylvania; ${ }^{2}$ Nuclear Medicine Technology, \\ Regis College, Weston, Massachusetts; and ${ }^{3}$ Instructional Management and Leadership, Robert Morris University, Moon Township, \\ Pennsylvania
}

This article discusses the process by which the Society of Nuclear Medicine Technology Section (SNMTS) is assisting educators as they transition to comply with the fourth edition of the Curriculum Guide for Educational Programs in Nuclear Medicine Technology. Methods: An electronic survey was sent to a list of nuclear medicine technology programs compiled by the educational division of the SNMTS. The collected data included committee member demographics, goals and objectives, conference call minutes, consultation discussions, transition examples, 4- and 2-y program curricula, and certificate program curricula. Results: There were 56 responses to the survey. All respondents were program directors, with 3 respondents having more than one type of program, for a total of 59 programs. Of these, 19 (33.93\%) were baccalaureate, 19 (28.57\%) associate, and 21 (37.5\%) certificate. Forty-eight respondents (85.71\%) had accreditation through the Joint Review Commission on Educational Programs in Nuclear Medicine Technology, 6 (10.71\%) had regional accreditation, and 2 (3.57\%) were accredited through other entities. Thirteen categories of required general education courses were identified, and the existing program curricula of $9(69.2 \%)$ courses were more than $50 \%$ compliant with the fourth edition Curriculum Guide. The fact that no measurable gap could be found within the didactic professional content across programs was due to the lack of a degree requirement and content standardization within the profession. The data indicated that the participating programs offer a minimum of 1-15 contact hours in emerging technology modalities. The required clinical hours ranged from 765 to 1,920 for degree or certificate completion. The average number of clinical hours required for all programs was 1,331.69. Conclusion: Standardization of the number and types of courses is needed both for current baccalaureate programs and for clinical education. This standardization will guide programs in transitioning from a certificate or associate level to the baccalaureate level. The greatest obstacle is in expanding curricula to meet the recommendations of the fourth edition Curriculum Guide. Such expansion to entry-level competency may be met by incorporating hybrid imaging courses, secondary-level

Received Nov. 9, 2011; revision accepted Feb. 6, 2012.

For correspondence or reprints contact either of the following:

Donna L. Mason, Robert Morris University, 6001 University Blvd., Moon

Township, PA 15108.

E-mail: mason@rmu.edu

Carly Pietrzyk, Robert Morris University, 6001 University Blvd., Moon

Township, PA 15108.

E-mail: pietrzyk.carly@gmail.com

Published online May 15, 2012.

COPYRIGHT (C) 2012 by the Society of Nuclear Medicine and Molecular Imaging, Inc. courses, and equivalency courses on the basic sciences and emerging technologies.

Key Words: baccalaureate level; curriculum changes; gap analysis survey; Curriculum Guide for Educational Programs in Nuclear Medicine Technology, 4th edition; transition

J Nucl Med Technol 2012; 40:178-182

DOI: 10.2967/jnmt.111.099622

\section{A}

2005 survey conducted by Dr. Paul Wing from the University of Albany (1) found that most respondents working in nuclear medicine technology (53.7\%) indicated they would "need further training in the [nuclear medicine] field." Authors Wing and Langelier (2), in another survey a year later, found that only $14 \%$ of active nuclear medicine technologists had earned a bachelor's degree. These findings were the impetus for an investigation by the Society of Nuclear Medicine Technology Section (SNMTS) concerning the transition process for nuclear medicine technology educational programs.

The SNMTS executive board charged the educational committee with the task of designing programmatic changes for the delivery of educational curricula within the profession of nuclear medicine technology. The committee was to develop a model in which 4 -y universities would collaborate with 2-y programs when planning curricula. They were also to determine the impact of the transition on programs and to use information from programs already in transition to assist existing programs. The final goal was to establish a transition model that would not result in any program attrition.

The educational committee selected a transition task force committee (TTFC) consisting of 14 volunteers with expertise in education, instructional design, or curriculum development, as well as familiarity with nuclear medicine technology. Five members of the TTFC were staff from baccalaureate programs, 5 were staff from certificate programs, 2 were staff from associate programs, and 2 were members of the SNMTS. Their objective was to devise criteria to identify gaps within educational programs, form recommendations for the transitioning process, and organize workshops for each program type in order to introduce the 4-y curricula 
and transition concepts. They were also to provide individual assessments and assistance for programs in developing a 4-y transition, such as the selection of online schools as possible articulation partners. The overall plan was to investigate potential transition blueprints by inviting schools to participate in developing structured models, with the final goal of sharing curricula with schools to help them design their programs and integrate them into the models.

\section{MATERIALS AND METHODS}

The process of collaboration within the TTFC began with an initial stage that allowed members to focus on the educational goals and begin a dialog on the information needed to strengthen delivery of these goals. Notes from conference calls and consultations were compiled chronologically and distributed.

Before meeting face-to-face in a 2-d workshop, members submitted a copy of their program design and curricula, including the course sequence, course descriptions, and any other relevant documentation. These materials were incorporated into tabulated binders to facilitate the workshop. The content of the binders was categorized and indexed according to the academic affiliations of the TTFC members and included member demographics, goals and objectives set forth by the SNMTS, minutes of conference calls and consultations, transition examples, 4- and 2-y program curricula, certificate program curricula, and SNMTS handouts entitled "Changes Impacting the Practice of Nuclear Medicine Technology and Student Education."

The workshop was held on November 6 and 7, 2008, at the Hyatt Regency in Reston, Virginia, and was attended by all 14 members. Day 1 included a review of the goals and objectives of the TTFC and an overview of the fourth edition of the Curriculum Guide for Educational Programs in Nuclear Medicine Technology (3). In discussions, the members assessed individual curricula and identified curriculum-related gaps. Critical to the process of determining transition methods for multiple schools was the application of members' unique expertise, as frontline educators, in their curriculum and subject matter. The committee was therefore divided into 4 breakout groups, each represented by a certificate, associate, and baccalaureate program director. The groups summarized their curricula as related to the fourth edition Curriculum Guide and then outlined recommendations for identifying and categorizing content gaps in each individual curriculum. Finally, the breakout groups presented the committee with a summary of their gap analysis findings and their recommendations.

On day 2 of the workshop, a gap analysis survey was developed. The survey was designed to measure data and information on individual program curricula. The first section of the survey asked respondents about the level of their program, their role in it, the type of accreditation offered, and which general education courses were required. The second section asked about the didactic professional core content of the entire program, measured in contact hours. The third section asked for the number of hours dedicated to emerging technologies in both didactic hours and clinical days. Respondents were also asked to indicate the total number of clinical hours in their program. The final section asked respondents about when they would be implementing changes within their curriculum based on the fourth edition Curriculum Guide.

The survey was launched on January 27, 2009, and was closed on March 9, 2009. It was sent electronically to a list of 116 nuclear medicine technology programs that the educational division of the SNMTS compiled from the American Registry of Radiologic Technologists, Nuclear Medicine Technology Board, and Joint Review Commission on Educational Programs in Nuclear Medicine Technology (JRCNMT) (4-8). All 116 of the listed educators were sent the electronic survey. Of these educators or their designees, 97 electronically opened the surveys, and 56 returned the surveys, giving a response rate of $57.7 \%$.

\section{RESULTS}

All respondents were program directors. Three respondents had more than 1 type of program, for a total of 59 programs, including 19 baccalaureate (33.93\%), 19 associate $(28.57 \%)$, and 21 certificate $(37.5 \%)$.

Programs may have institutional or programmatic accreditation. Programmatic accreditation is granted by the JRCNMT, the only accreditation body for nuclear medicine technology education in the United States. Accreditation focuses on the clinical component of the program and the competency of students. An example of institutional accreditation is the Middle States Commission on Higher Education, a unit of the Middle States Association of Colleges and Schools that accredits degree-granting colleges and focuses on the overall educational process of an institution. The survey asked about type of accreditation because it might be a factor in a program's decision to consider the recommendations of the fourth edition Curriculum Guide. Forty-eight respondents $(85.71 \%)$ had accreditation through the JRCNMT, 6 via regional accreditation (10.71\%), and 2 (3.57\%) through other entities. The category "other" did not include a field for entering the specific type of accreditation entity.

\section{Required General Education Courses}

Table 1 summarizes the general education courses required by the respondents' degree program structure.

TABLE 1

Required General Education Courses

\begin{tabular}{lc}
\hline \multicolumn{1}{c}{ Required courses } & $\begin{array}{c}\text { Programs requiring } \\
\text { course }\end{array}$ \\
\hline General physics I & $76.79 \%$ \\
\hline General physics II & $32.14 \%$ \\
General chemistry I & $94.64 \%$ \\
General chemistry II & $42.86 \%$ \\
Human anatomy and physiology I & $96.43 \%$ \\
Human anatomy and physiology II & $73.21 \%$ \\
College algebra & $82.14 \%$ \\
Statistics & $44.64 \%$ \\
Advanced mathematics & $26.79 \%$ \\
\hline Oral communications & $73.21 \%$ \\
\hline Written communications & $82.14 \%$ \\
\hline Humanities & $57.14 \%$ \\
\hline Social Science & $51.79 \%$ \\
\hline
\end{tabular}




\section{Optional Didactic Content}

The category defined in the fourth edition Curriculum Guide as optional didactic content was also assessed. Table 2 displays these courses and the percentage of programs offering them.

\section{Didactic Professional Content}

Table 3 categorizes the didactic professional courses and summarizes the percentage of programs that offer more than 18 contact hours (defined as the time the student spent on the total amount of formal didactic course work as opposed to the academic credit hour corresponding to the course). The lowest-percentage categories were counting statistics, pediatrics, and medical informatics.

\section{Inclusion of Emerging Technologies in Didactic Content and Clinical Hours}

Figure 1 illustrates the didactic course hours related to 5 categories of emerging technology. Participating programs offer a minimum of 1-15 contact hours in these technologies. Figure 2 measures the same 5 categories in terms of days covered within a clinical setting on site or at a hospital.

\section{Total Clinical Hours Required by Individual Programs}

Data on the total number of clinical hours required by each degree program were analyzed using the Statistical Package of Social Sciences, version 15.0 (SPSS Inc.), for Windows (Microsoft). For degree or certificate completion, the hours ranged from 765 to 1,920 , with an SD of 261.20 and an average of 1,331.69. For statistical purposes, the calculations were tabulated after removal of the director who responded "not sure."

\section{DISCUSSION}

The fourth edition Curriculum Guide has been revised to "include the expanding and increasingly complex educational content that is necessary for preparing knowledgeable, competent, and qualified entry level nuclear medicine technologists." The TTFC designed the gap analysis survey to assess the compliance of nuclear medicine technology programs with the educational curriculum guidelines of the fourth edition Curriculum Guide.

TABLE 2

Optional Didactic Course Work

\begin{tabular}{lr}
\hline \multicolumn{1}{c}{ Optional didactic courses } & $\begin{array}{r}\text { Programs offering } \\
\text { course }\end{array}$ \\
\hline Biology & $23.21 \%$ \\
\hline Molecular biology & $1.79 \%$ \\
\hline Genetics & $1.79 \%$ \\
\hline Pathophysiology & $17.86 \%$ \\
\hline Immunology & $7.14 \%$ \\
\hline Biomedical ethics & $25 \%$ \\
\hline Health care management courses & $7.14 \%$ \\
\hline Medical terminology & $73.21 \%$ \\
\hline Advanced mathematics & $26.79 \%$ \\
\hline Computer science & $50 \%$ \\
\hline
\end{tabular}

TABLE 3

Didactic Professional Course Work

\begin{tabular}{|c|c|}
\hline $\begin{array}{l}\text { Didactic professional } \\
\text { course work }\end{array}$ & $\begin{array}{c}\text { Programs } \\
\text { offering }>18 \\
\text { contact hours }\end{array}$ \\
\hline Patient care & $58.93 \%$ \\
\hline Health sciences research & $19.64 \%$ \\
\hline Ethics and law & $12.50 \%$ \\
\hline Cross-sectional anatomy & $26.79 \%$ \\
\hline Systems-based practice & $12.50 \%$ \\
\hline Medical informatics & $5.36 \%$ \\
\hline Radiobiology & $39.29 \%$ \\
\hline Radiation protection & $57.14 \%$ \\
\hline Radiation physics & $66.07 \%$ \\
\hline Instrumentation & $75.00 \%$ \\
\hline Instrumentation: nonimaging & $30.36 \%$ \\
\hline Instrumentation: counting statistics & $3.57 \%$ \\
\hline Instrumentation: computers & $28.57 \%$ \\
\hline Instrumentation: imaging & $62.50 \%$ \\
\hline Nuclear pharmacy & $69.64 \%$ \\
\hline Pharmacology & $16.07 \%$ \\
\hline Diagnostic procedures & $80.36 \%$ \\
\hline Diagnostic procedures: skeletal & $12.50 \%$ \\
\hline Diagnostic procedures: cardiovascular & $41.07 \%$ \\
\hline $\begin{array}{l}\text { Diagnostic procedures: central } \\
\text { nervous system }\end{array}$ & $8.93 \%$ \\
\hline $\begin{array}{l}\text { Diagnostic procedures: digestive } \\
\text { system }\end{array}$ & $19.64 \%$ \\
\hline $\begin{array}{l}\text { Diagnostic procedures: } \\
\text { endocrine/exocrine }\end{array}$ & $17.86 \%$ \\
\hline Diagnostic procedures: genitourinary & $12.50 \%$ \\
\hline $\begin{array}{l}\text { Diagnostic procedures: hematology } \\
\text { and in vitro }\end{array}$ & $7.14 \%$ \\
\hline $\begin{array}{l}\text { Diagnostic procedures: respiratory } \\
\text { system }\end{array}$ & $7.14 \%$ \\
\hline $\begin{array}{l}\text { Diagnostic procedures: infection } \\
\text { and inflammation }\end{array}$ & $14.29 \%$ \\
\hline Diagnostic procedures: oncology & $17.86 \%$ \\
\hline Diagnostic procedures: pediatrics & $3.57 \%$ \\
\hline
\end{tabular}

\section{Recommended General Education Courses}

Most programs are currently in compliance with several general education courses recommended by the SNMTS, including general physics I, general chemistry I, human anatomy and physiology I and II, college algebra, and oral and written communication. Physics I was not required by $23.21 \%$ of the programs (Table 1 ).

To be in compliance, $67.86 \%$ of the programs would need to incorporate second-semester or equivalent course work in physics, $57.14 \%$ in general chemistry, and $26.79 \%$ in human anatomy and physiology.

Another significant programmatic gap was identified for course work in statistics, humanities, advanced mathematics, and social sciences, with less than $60 \%$ of the programs surveyed currently offering these courses. For programs to meet the recommendations of the fourth edition Curriculum Guide, they would need to incorporate these 3 additional courses in their existing curricula.

Additionally, a programmatic gap was discovered in the category defined as optional preparatory course work (Table 


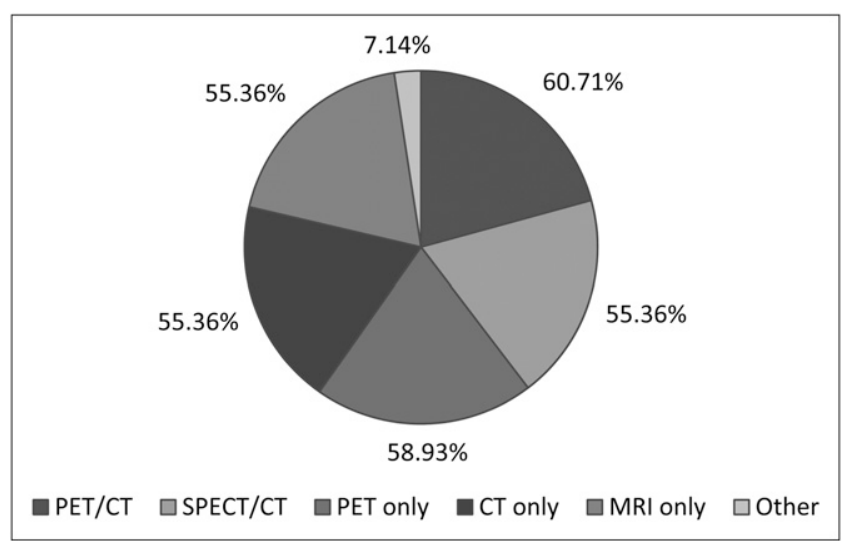

FIGURE 1. Emerging technologies included in didactic content hours (1-15 h).

2). The most significant gaps in this course work occurred in the areas of molecular biology, genetics, immunology, and health care management. Other course work in this area included biology, pathophysiology, biomedical ethics, and computer science. Although these are considered optional courses, they are recommended to strengthen the didactic portion of programs.

The transition of most current programs to entry-level competency according to the fourth edition Curriculum Guide would involve the addition of course work related to physics, chemistry, statistics, humanities, and social sciences. The addition of these courses would allow programs to meet the minimum competency standards as specified by the SNMTS. In addition, it is recommended that programs add several optional courses such as biology and pathophysiology.

\section{Didactic Professional Content Hours}

All areas of didactic content are currently being covered or offered for a minimum of 1-7 didactic hours. Most didactic course work involves diagnostic procedures, with $80.36 \%$ of respondents indicating that students spent 18 or

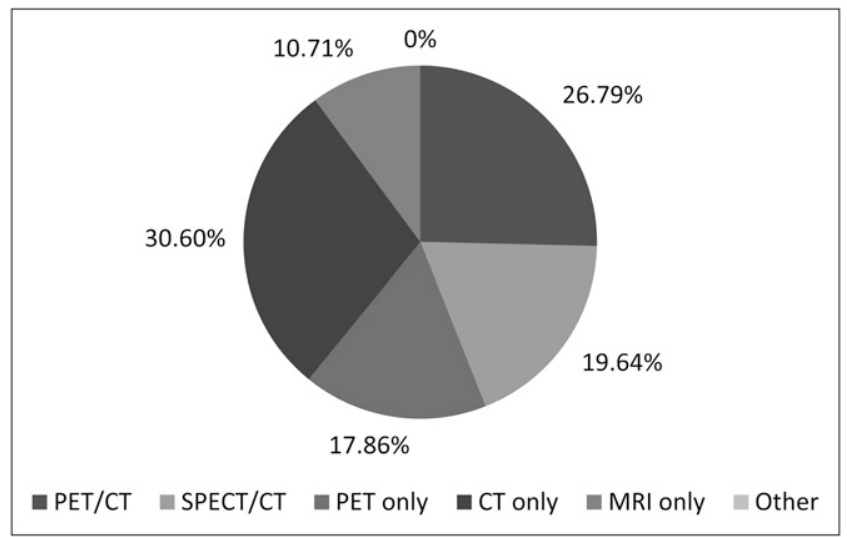

FIGURE 2. Emerging technologies included in clinical days $(1-7 \mathrm{~d})$. more hours on this content area (Table 3). Other prevalent content coverage includes instrumentation (75\%), nuclear pharmacy $(69.64 \%)$, radiation physics $(66.07 \%)$, imaging instrumentation $(62.50 \%)$, patient care $(58.93 \%)$, and radiation protection $(57.14 \%)$. Overall, there is not a measurable gap within the didactic professional content. Differences in didactic hour distribution are likely due to differences in individual requirements for program degree levels.

\section{Emerging Technologies in Didactic Content and Clinical Hours}

The programs offer a minimum of $1-15 \mathrm{~h}$ of didactic course work and 1-7 d in a clinical setting (Figs. 1 and 2). On the basis of these results, all programs are providing exposure to emerging technologies in both a didactic and a clinical setting. To become registry-eligible for additional certification in emerging technologies, programs would have to include additional course work and clinical hours - an issue that was not addressed in the survey.

\section{Total Clinical Hours Required by Individual Programs}

There is a wide range of required clinical hours for individual programs. The number of clinical hours is determined largely by the length of each program. In comparison with 24- to 36-mo programs, a 12-mo program can require only a limited number of hours. This factor is important when one is attempting to demonstrate true competency in nuclear medicine procedures and therapies. The traditional model of "see one, do one" skills is no longer justified in view of the knowledge required to understand true molecular imaging with various modalities, pathophysiology, and immunology. Clinical education should focus not on "how" to do the procedure but rather on the "why." To be more effective practitioners, nuclear medicine technologists need to be educated on the reasoning behind performing specific procedures.

\section{Limitations}

This survey failed to differentiate between certificate, certification, associate, and baccalaureate programs when collecting data. Further research should explore the differences in each program level to better understand which courses are typically offered within certificate or associate programs versus baccalaureate programs. The transition guide could then focus specifically on what is needed to move programs toward the baccalaureate level.

\section{CONCLUSION}

This study was an introductory investigation of the current offerings of nuclear medicine technology programs. The wide variety of ways in which programs can meet minimum requirements creates a challenge in standardizing education within the profession. To advance the field, a common ground has to be established among all programs. In support of the SNMTS initiative for entry-level education, standardization of the number and types of courses is needed both for current baccalaureate programs and for clinical education. From this 
standardization, a guide can be devised to help programs transition from a certificate or associate level to the baccalaureate level. Thus, current programs may meet the entry-level competency requirements of the fourth edition Curriculum Guide.

\section{ACKNOWLEDGMENTS}

Additional members of the TTFC include Pamela Alderman, Norman Bolus, Elizabeth Duncan, William Hubble, Kathy Hunt, Cybil Nielson, Lessa Ann Ross, Leroy Stecker, Douglas Warner, Lynn Barnes, and Nikki Wenzel. No potential conflict of interest relevant to this article was reported.

\section{REFERENCES}

1. Nuclear medicine technologists in the U.S.: findings from a 2005 survey. Society of Nuclear Medicine Web site. Available at: http://www.snm.org/docs/Nuclear_
Medicine_Technologist_Report_2005.pdf. Published September 2006. Revised January 2007. Accessed May 1, 2012.

2. Wing P, Langelier MH, De AP. Nuclear medicine scientists: findings and recommendations based on a 2006 survey. J Nucl Med. 2007;48(4):11N-14N.

3. Nielsen C, Aaron L, Bolus NE, et al. Curriculum guide for educational programs in nuclear medicine technology, 4th ed. American Society of Radiologic Technologists Web site. Available at: https://www.astt.org/Media/pdf/Educators/SNMTSCurriculum Guide4thEd.pdf. Published August 5, 2006. Accessed May 1, 2012.

4. Nuclear medicine technology didactic and clinical competency requirements: eligibility requirements effective January 2011. American Registry of Radiologic Technologists Web site. Available at: https://www.arrt.org/pdfs/Disciplines/Competency-Requirements/ NMT-Competency-Requirements.pdf. Accessed May 2, 2012.

5. Nuclear medicine exam: components of preparedness. NMTCB Web site. Available at: http://www.nmtcb.org/exam/cops.php. Accessed May 2, 2012.

6. Nuclear medicine exam: components of preparedness-group III: clinical procedures. NMTCB Web site. Available at: http://www.nmtcb.org/exam/cops.php\#GROUP3. Accessed May 2, 2012.

7. Nuclear medicine exam: task list—procedure list. NMTCB Web site. Available at: http://www.nmtcb.org/exam/tasklist.php. Accessed May 2, 2012.

8. Curriculum guide for educational programs in nuclear medicine technology, 4th edition. Society of Nuclear Medicine Web site. Available at: http://interactive. snm.org/docs/snmts_curriculum_guide_4th_ed.pdf. Published August 5, 2008. Accessed May 8, 2012. 